\title{
INTEGRATED MONOLITHIC CRYSTAL FILTER FOR CITIZEN BAND TRANSCEIVERS
}

\author{
MASAAKI ONO, SHIGEO TANJI and HIDEKI TOMINAGA
}

Fujitsu Limited, 1015 Kamikodanaka, Nakahara-ku, Kawasaki, 211, Japan

\begin{abstract}
This paper will describe a SSB $10.7 \mathrm{MHz}$ IF filter for CB band transceivers employing an integrated capacitor circuit and four dual mode Monolithic Crystal Filters (MCFs) of AT cut Quartz. With a narrow bandwidth of $2 \times 10^{-4}$, an insertion loss of less than $5 \mathrm{~dB}$, and a low temperature coefficient of the center frequency of within \pm 20 ppm over the range of -35 to $+65^{\circ} \mathrm{C}$, this filter also meets mechanical shock-resistance requirements. The integrated capacitor circuit consists of thin film $\mathrm{Ta}_{2} \mathrm{O}_{5}$ capacitors and interdigital gap capacitors formed on both sides of a Fine Grain Alumina (FGA) substrate. Four MCFs are directly soldered to the substrate of the integrated capacitor circuit, allowing this filter to be made smaller and lighter and have better resistance to mechanical shock. Also important, the manufacturing process is suitable for mass production.
\end{abstract}

\section{INTRODUCTION}

Filters play an extremely important role in determining the characteristics of radio communications equipment. As the popularity of SSB Citizen Band (CB) radio has grown, the demand for rugged transceivers for use in automobiles has also grown. The IF filters used in these transceivers not only must be able to withstand the severe shocks that mobile radios are inevitably subject to. And of course, they must meet rigid electrical specifications.

To provide narrow band width and sufficient stop band attenuation in conventional IF filters requires the inclusion of many discrete components, such as crystal resonators and capacitors. The components are arranged in a complicated network and mounted on a printed circuit board. The recently developed monolithic crystal filters (MCFs) combine two crystal resonators and a transformer into a single unit. However, the MCFs are hermetically sealed in individual cases for high reliability and stability, and many discrete capacitors are still mounted on a circuit board and sealed in a can. Both types require many components so that the end result is bulky and heavy. Moreover, even so, great care is required in the assembly process, which is not amenable to mass production, and these filters are inferior in their resistance to mechanical shocks.

In this paper, we explain the integrated monolithic crystal filter we developed for SSB transceivers. This filter consists of a single integrated capacitor circuit and four MCFs. The integrated capacitor circuit contains thin film $\mathrm{Ta}_{2} \mathrm{O}_{5}$ capacitors, interdigital gap capacitors, and conductor patterns for mounting and connecting the MCFs, which are fabricated on both sides of FGA substrate using thin film hybrid techniques. Four dual mode MCFs are mounted on an integrated capacitor circuit, two inside and two outside.

\section{DESIGN OF MONOLITHIC CRYSTAL FILTERS FOR SSB TRANSCEIVERS}

Electrical target values of IF filters for SSB transceivers are shown in Table 1 . They must achieve the narrow bandwidth between 2.2 and $2.5 \mathrm{kHz}$ with ripple of less than $2 \mathrm{~dB}$, a low insertion loss of less than $5 \mathrm{~dB}$, a sharp attenuation skirt of more than $15 \mathrm{~dB}$ within $\pm 3 \mathrm{KHz}$ and more than $60 \mathrm{~dB}$ within $\pm 6 \mathrm{KHz}$, guarantee attenuation of more than $80 \mathrm{~dB}$, and have a low temperature coefficient of $\pm 30 \mathrm{ppm}$ in the range of -35 to $65^{\circ} \mathrm{C}$. The element of the filter is required to have an extremely high quality factor for resonance $\mathrm{Q}$ of more than $7 \times 10^{4}$ and a low temperature coefficient of less than $\pm 25 \mathrm{ppm}$ so that the filter can meet these electrical requirements.

Typical networks of IF filters for SSB transceivers are shown in Figure 1. (a) is a network composed of discrete $\mathrm{L}, \mathrm{C}$ elements. A number of $\mathrm{L}, \mathrm{C}$ elements are necessary. Generally speaking, Q of discrete L, C elements is so low that it is impossible to realize a filter meeting the above specifications. (b) is a filter in which some discrete $\mathrm{L}, \mathrm{C}$ elements are replaced by crystal resonators and this is a commonly used type. On the 
TABLE I

Target value of IF filter for SSB transceiver.

\begin{tabular}{ll}
\hline Description & Characteristics \\
\hline Centre frequency (f.) & $10.6935 \mathrm{MHz} \pm 200 \mathrm{~Hz}$ \\
$6 \mathrm{~dB}$ band width ( $\Delta \mathrm{f})$ & $2.2 \mathrm{KHz} \leqq \Delta \mathrm{f} \leqq 2.5 \mathrm{kHz}$ \\
Ripple & $\leqq 2 \mathrm{~dB}$ \\
Insertion loss & $\leqq 5 \mathrm{~dB}$ Input power level \\
& $\leqq 3 \mathrm{KHz}$ at $15 \mathrm{~dB}$ \\
Attenuation band width & $\leqq 4 \mathrm{KHz}$ at $50 \mathrm{~dB}$ \\
Guarantee attenuation & $\geqq 80 \mathrm{~dB}$ at $\pm 3.5 \mathrm{~K} \pm 1 \mathrm{MHz}$ \\
Terminal impedance & $600 \Omega \| 15 \mathrm{pF}$ Both Inside \\
& and Outside \\
Temperature range & $\pm 25 \mathrm{ppm}$ at $-35 \sim+65^{\circ} \mathrm{C}$ \\
\hline
\end{tabular}

other hand, recently developed dual mode MCFs which combine two crystal resonators and a transformer into a single unit, enables the number of crystal resonators, capacitors, and transformers in the filter to be decreased as shown in Figure 1 (c) while discrete capacitors are still employed. The filter shown in Figure 1 (d) which we developed basically belongs to type (c). But in this filter, capacitors and conductors connecting MCFs are fabricated as an integrated capacitor circuit on both sides of the FGA substrate using hybrid IC techniques. Four MCFs are mounted on both sides of
TABLE II

Design of dual mode MCF and capacitors for SSB IF filter.

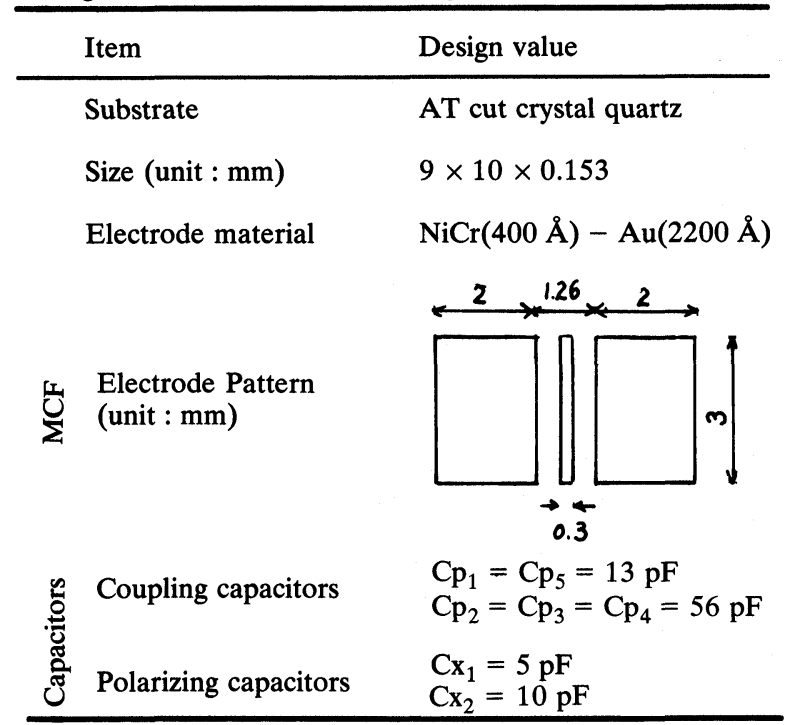

the substrate. The value of these elements can be determined by the image ${ }^{1}$ or operating, ${ }^{2}$ parameter filter design method. The results obtained by design using the image parameter method are shown in Table II.

Individual MCFs employing the thickness shear vibration mode of AT cut Quartz are designed to have th same characteristics in order to make the manufacturing process easier. $\mathrm{Cx}_{1}$ and $\mathrm{Cx}_{2}$ are capacitors for obtaining sharp attenuation of MCF with pole.

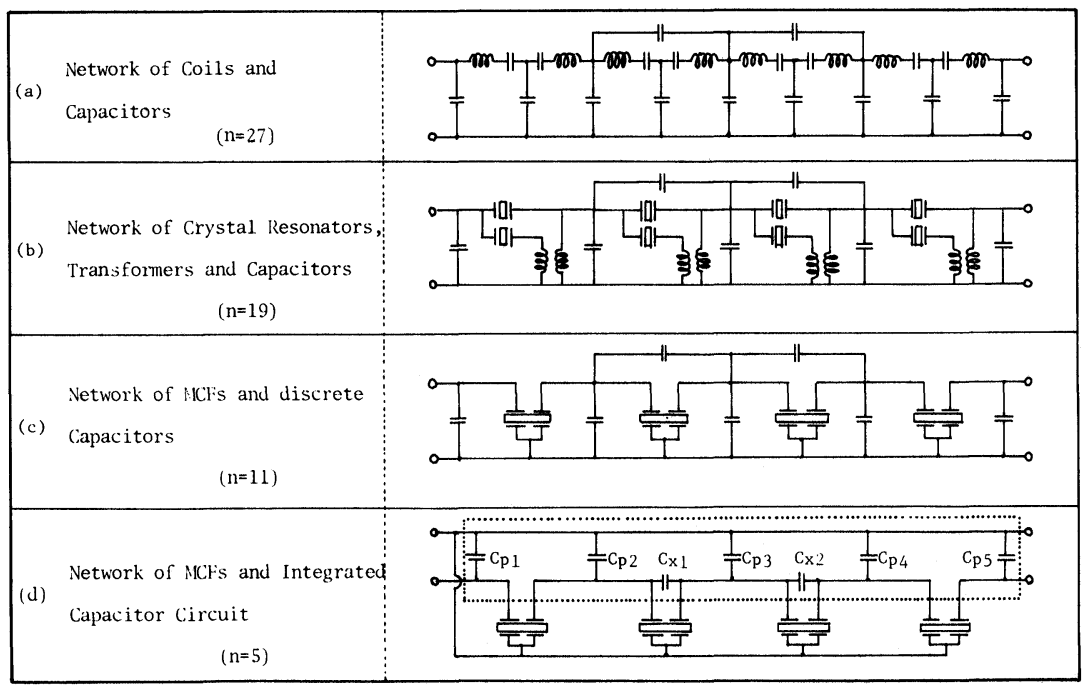

FIGURE 1 Circuit diagrams of IF filter for SSB transceiver. 


\section{HYBRID STRUCTURE OF CB BAND FILTER}

This filter developed for SSB transceivers basically consists of an integrated capacitor circuit and four dual mode MCFs. The manufacturing process and typical characteristics of this filter are described in this paper.

\section{(A) Dual Mode $M C F$}

The manufacturing process flowchart of this dual mode MCF is outlined in Figure 2. The quartz ingot is first finished into the AT cut plates with the specified dimension shown in Table II. After NiCr-Au electrodes with thickness of $400 \AA$ and $2000 \AA$ respectively are evaporated on both sides of this plate, copper leads are soldered to the edges of the electrodes. The reason why

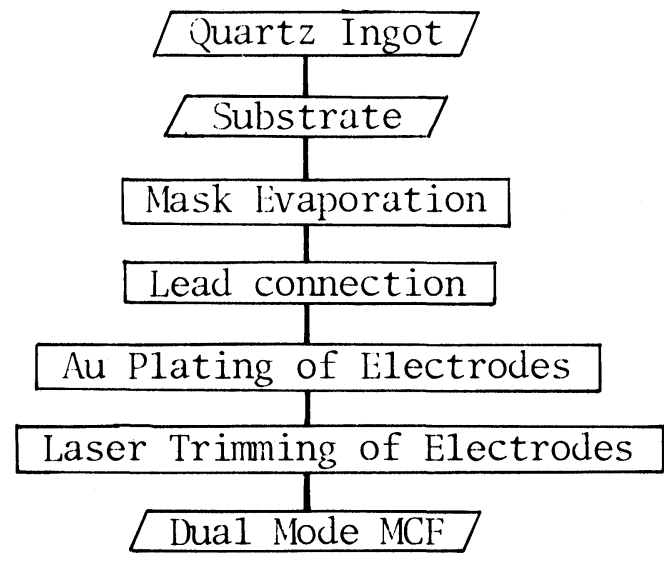

FIGURE 2 Major process steps of dual mode MCF. the leads are attached to the MCF are as follows:

a) to test the characteristics of the dual mode MCF itself before it is mounted.

b) so as not to change the characteristics of the MCF after it is mounted.

c) to absorb thermal stress occurring due to the difference in thermal expansion between the Quartz and the FGA substrate and mechanical shock.

The MCF is plated with Au for rough tuning of frequency. Further, it is trimmed using a YAG laser for tuning its bandwidth and fine tuning its frequency. Typical impedance response of the dual mode MCF after tuning is shown in Figure 4. Its image impedance is about $600 \mathrm{ohm}$ according to the desired value.

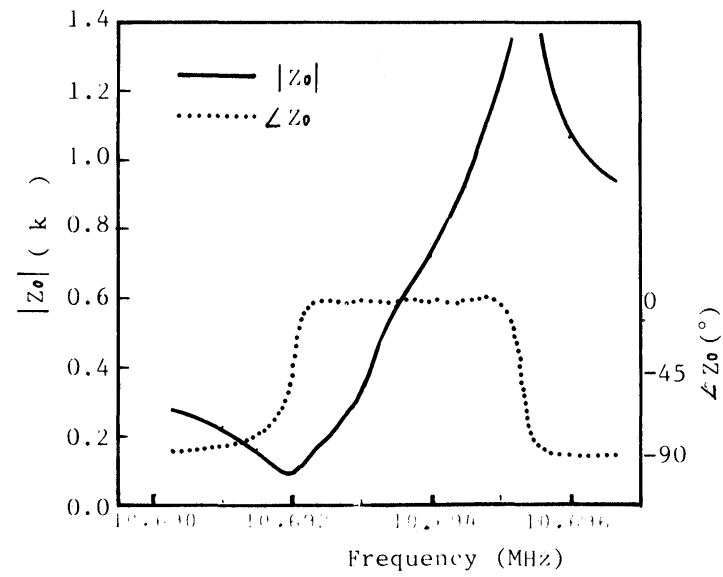

FIGURE 4 Image impedance of dual mode MCF.

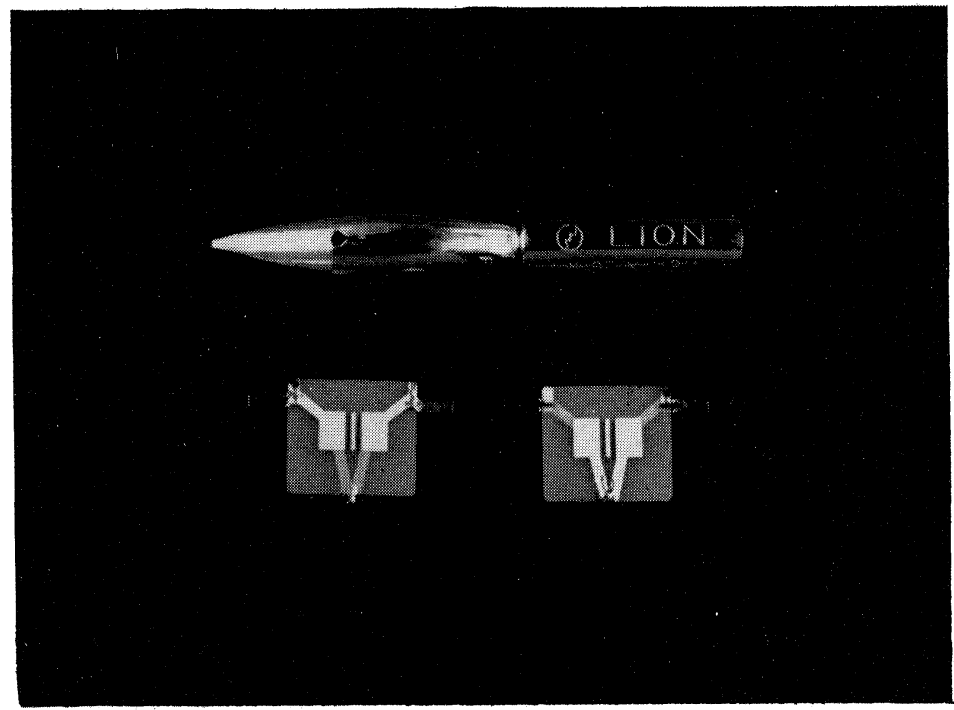

FIGURE 3 Configuration of dual mode MCF. 


\section{(B) Integrated Capacitor Circuit}

The manufacturing process flowchart of the integrated capacitor circuit is outlined in Figure 5. Fine Grain

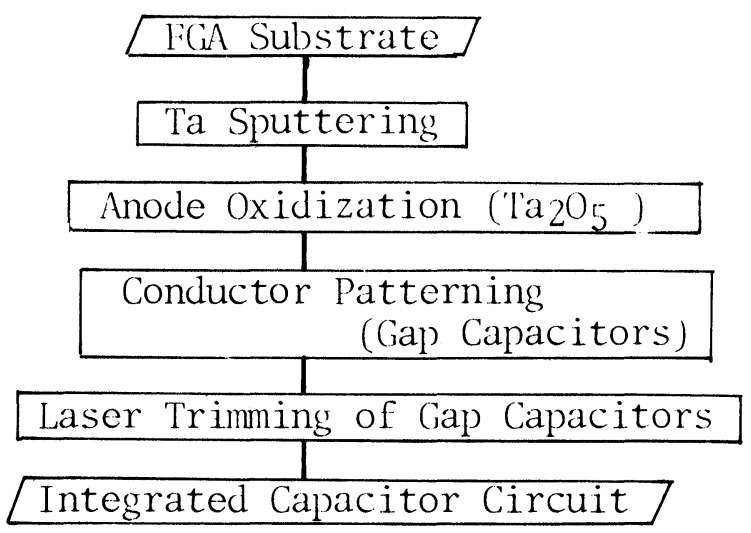

FIGURE 5 Major process steps of integrated capacitor circuit.

Alumina (FGA) substrate is used for the fabrication of thin films. FGA is the non-glazed Alumina substrate developed by Fujitsu and it is possible to fabricate thin films easily on both sides of it. ${ }^{3} \mathrm{~A}$ Ta film is first sputtered on the FGA and is anodic oxidized to $\mathrm{Ta}_{2} \mathrm{O}_{5}$. Further, electrodes are fabricated on the $\mathrm{Ta}_{2} \mathrm{O}_{5}$ film to form bipolar TM capacitors. At the same time interdigital gap capacitors and conductor patterns are formed. Finally the interdigital capacitors are trimmed to the specified values.

Capacitances of 5 to $60 \mathrm{pF}$ are necessary for this filter. Capacitances of less than $5 \mathrm{pF}$ can be realized by interdigital capacitors and those of more than $5 \mathrm{pF}$ can be realized by the TM capacitors themselves or by combinations of TM and gap capacitors. Capacitance distributions of each type capacitor are shown in Figure 7. Capacitance distributions of TM capacitors $\mathrm{Cp}_{2}, \mathrm{Cp}_{3}$, and $\mathrm{Cp}_{4}$ are within $7 \% . \mathrm{Cp}_{1}, \mathrm{Cp}_{2}, \mathrm{Cx}_{1}$, and $\mathrm{Cx}_{2}$ can be trimmed to their specified capacitances. Figure 6 shows the finished integrated capacitor circuit. Capacitors are fabricated on one side of the FGA as shown in Figure 6 (a) and conductors on the other side as shown in Figure 6 (b).

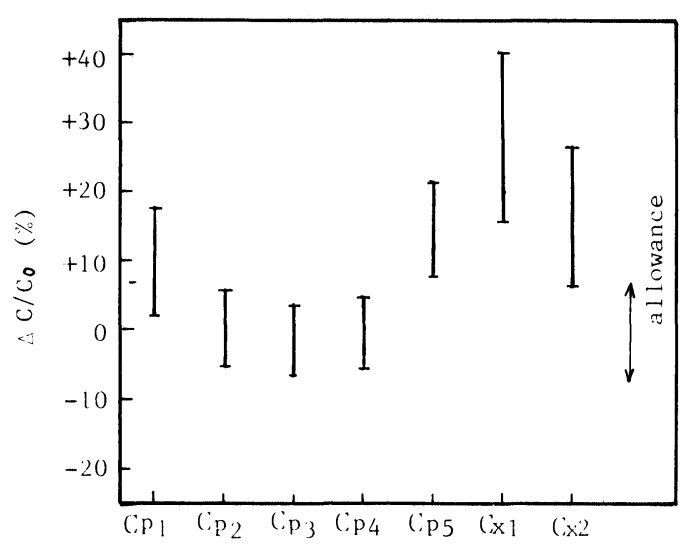

FIGURE 7 Variation of capacitance on integrated capacitor circuit. $\mathrm{Cp}_{1}, \mathrm{Cp}_{5}, \mathrm{Cx}_{1}$ and $\mathrm{Cx}_{2}$ are adjustable capacitors.

\section{ASSEMBLY}

The process flowchart of assembly of MCFs, integrated capacitor circuits and stems is shown in Figure 8. The

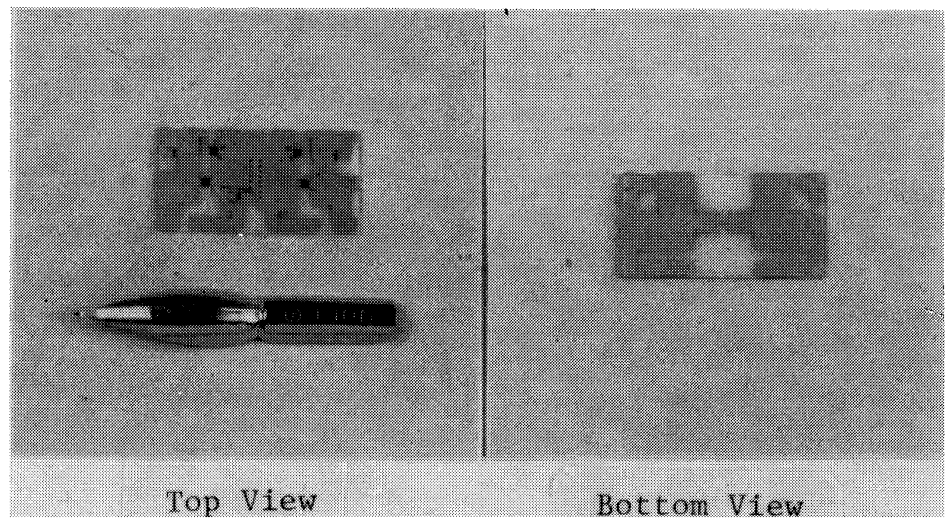

FIGURE 6 Configuration of integrated capacitor circuit. $6 \mathrm{Ta}_{2} \mathrm{O}_{5}$ thin film capacitors and 4 gap capacitors on the top side, and only the conductor pattern on the bottom side. 


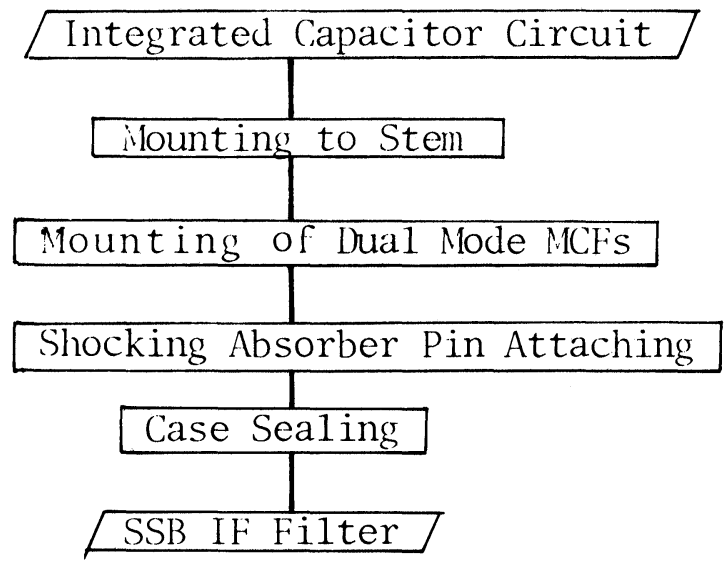

FIGURE 8 Assembly of SSB IF filter.

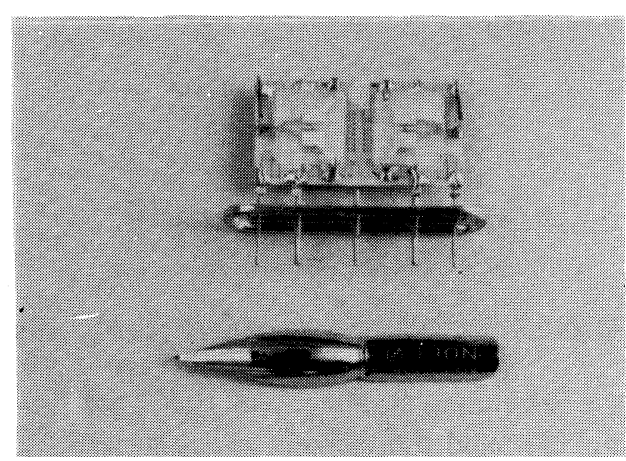

FIGURE 9 Assembly filter.

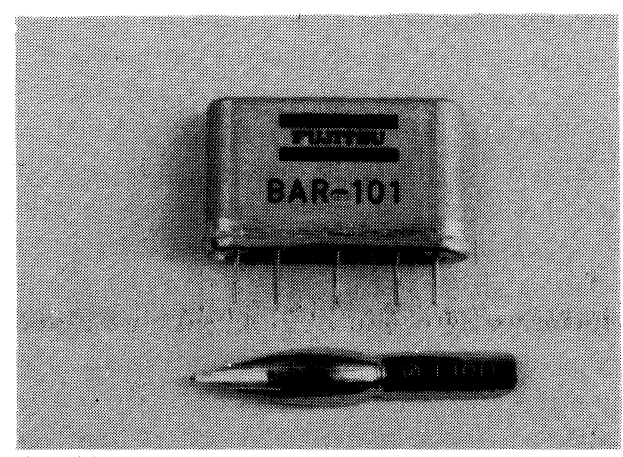

FIGURE 10 SSB IF filter.

integrated capacitor circuit is first soldered on the stem and two pins are soldered on the upper side of substrate to electrically connect inside and outside. Four frequency tuned MCFs are soldered on both sides of the integrated capacitor circuit, two inside and two outside as shown in Figure 9. Further two pins are soldered on the corners of the substrate to absorb mechanical shocks. After assembly, it is cleaned and sealed in a hermetic case filled with $\mathrm{N}_{2}$. Photograph of a finished unit is shown in Figure 10. The dimensions of this filter are $35 \mathrm{~mm}$ long, $8 \mathrm{~mm}$ wide and $20 \mathrm{~mm}$ high. This makes it half of its volume and $1 / 3$ of the weight of conventional filters.

\section{TEST RESULTS}

Test results of this newly developed filter are shown in Figures 11, 13, 14 and 15. Figure 11 shows the typical amplitude response which was measured using a circuit with an input impedance of $600 \mathrm{ohm} / / 15 \mathrm{pF}$ and an output impedance of $600 \mathrm{ohm} / / 15 \mathrm{pF}$. It has insertion loss of less $4 \mathrm{~dB}$, ripple of $1.5 \mathrm{~dB}, 6 \mathrm{~dB}$ bandwidth of 2.2 to $2.5 \mathrm{kHz}, 15 \mathrm{~dB}$ bandwidth of less than $3 \mathrm{kHz}, 60$ $\mathrm{dB}$ bandwidth of less than $4 \mathrm{kHz}$, and guaranteed attenuation of more than $80 \mathrm{~dB}$.

Figure 13 shows the results of a drop test. Even after dropping the filter onto a wooden board from a height of $80 \mathrm{~cm}$ in the $X, Y, Z$ directions, 3 times each, the variation of the centre frequency was within $\pm 4 \mathrm{ppm}$. This makes it highly superior to conventional filters which consist of discrete crystal resonators and capacitors, which are damaged after a $40 \mathrm{~cm}$ drop test.

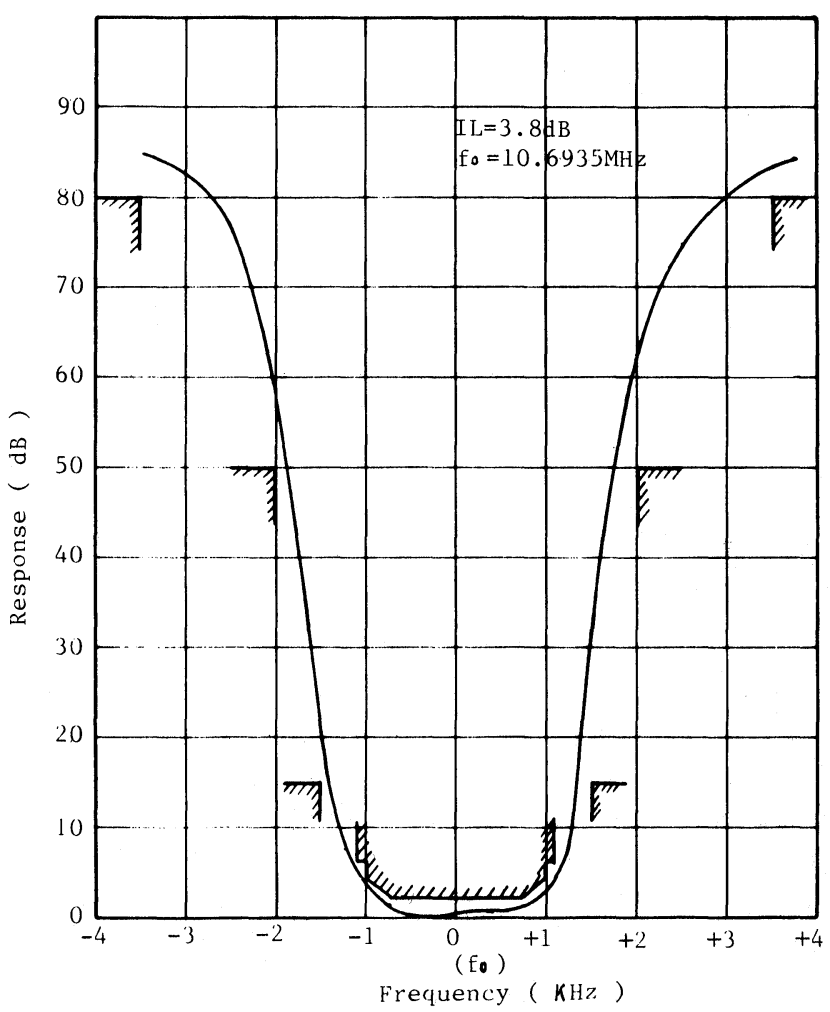

FIGURE 11 Typical frequency response of SSB IF filter. 


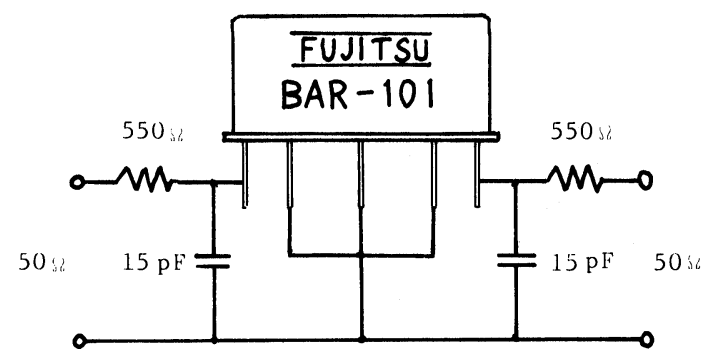

FIGURE 12 Measuring circuit.

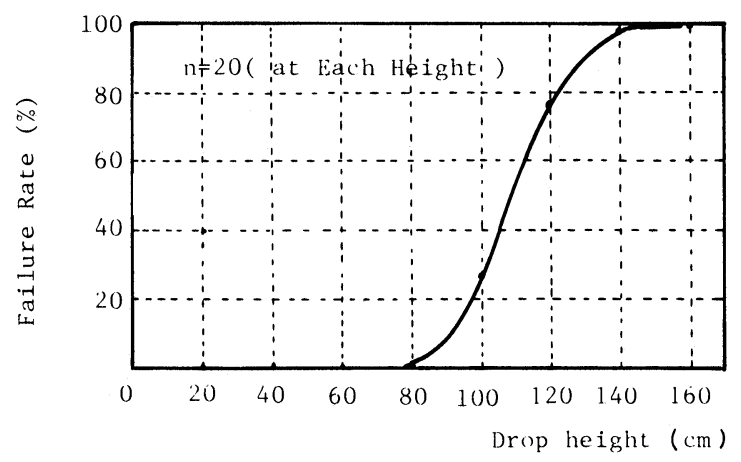

FIGURE 13 Drop test results.

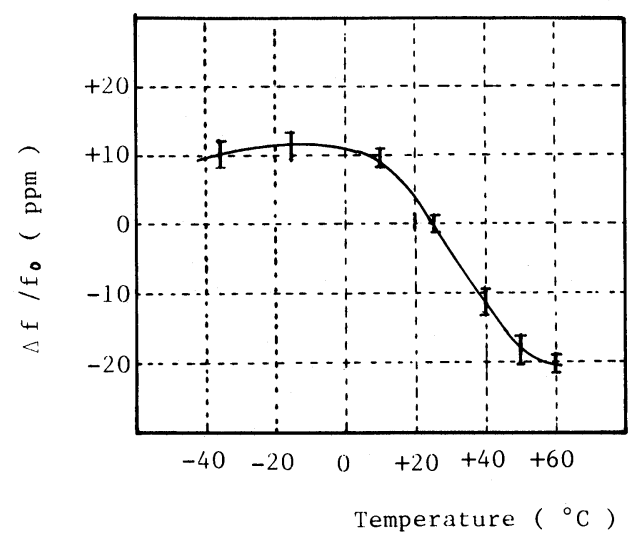

FIGURE 14 Temperature characteristics.

This is due to its simple structure consisting only of an integrated capacitor circuit and MCFs decreasing the number of components and the weight of the filter.

Figure 14 shows the temperature coefficient of the centre frequency of this filter. $\pm 20 \mathrm{ppm}$ was obtained. That is almost the temperature coefficient of AT cut Quartz itself in spite of the fact that MCFs are directly mounted on the integrated capacitor circuit. Mounting and capacitor circuit make only a slight difference.
Figure 15 shows the results of life test at a temperature of $+65^{\circ} \mathrm{C}$ without load. The variation of the centre frequency is within $\pm 15 \mathrm{ppm}$, so there is no obstacle to its use in practice.

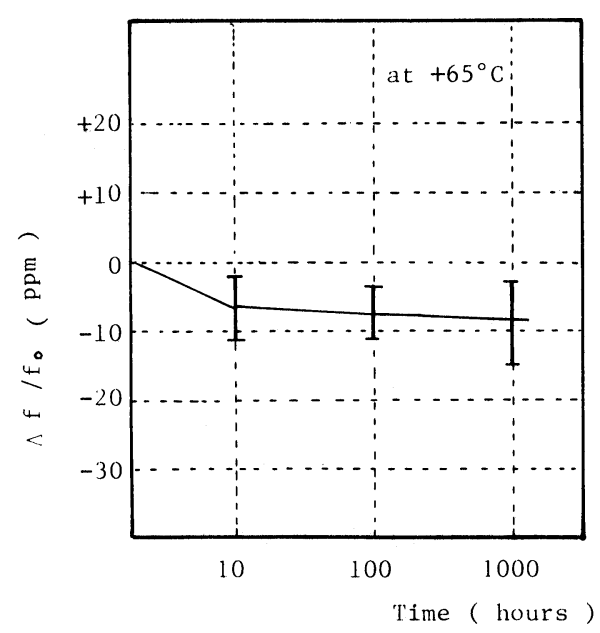

FIGURE 15 Life test results.

\section{CONCLUSIONS}

We have developed an integrated $10.7 \mathrm{MHz}$ SSB IF filter for CB band transceivers which meets FCC standards.

Four dual mode MCFs at AT cut Quartz and seven capacitors for connecting these MCFs are first designed using the image parameter filter design method.

The dual mode MCFs consist of AT cut Quartz plate carefully finished to a specified thickness, an electrode pattern evaporated onto the plate, and three copper leads attached on the edge of each electrode. The integrated capacitor circuit of $\mathrm{Ta}_{2} \mathrm{O}_{5}$ capacitors and interdigital gap capacitors is fabricated on both sides of the FGA substrate. Four dual mode MCFs are soldered on both sides of the integrated capacitor circuit. This densely integrated filter consists of only five components makes it much smaller and lighter than conventional filters consisting of about 27 components.

Test results showed that this filter meets amplitude response, temperature, and mechanical shock resistance requirements. In fact the resistance to mechanical shock is about twice that of ordinary filters, making the filters suitable for transceivers mounted in automobiles.

Twenty integrated capacitor circuits can be obtained from one substrate and assembly is simple. Thus, this filter is superior to conventional ones in suitability for mass production. 


\section{ACKNOWLEDGEMENTS}

The authors are grateful to Dr. H. Sasaki, Dr. Y. Nishimura, Mr. T. Namikata, Dr. T. Hara and Dr. N. Wakatsuki for stimulating discussions and adequate advice.

\section{REFERENCES}

1. H. Watanabe and H. Shimizu, The 39th electromechanical functional device standing committee data. p. 13-19, Oct. 30, (1974).

2. T. Ashida, 57-A.5 IECE of Japan, page 337, (1973).

3. K. Niwa, J. Nakamura and K. Murakawa, IEEE, Trans, on Parts, Hybrids and Packaging, Vol. PHP-10, p. 262, (1974). 

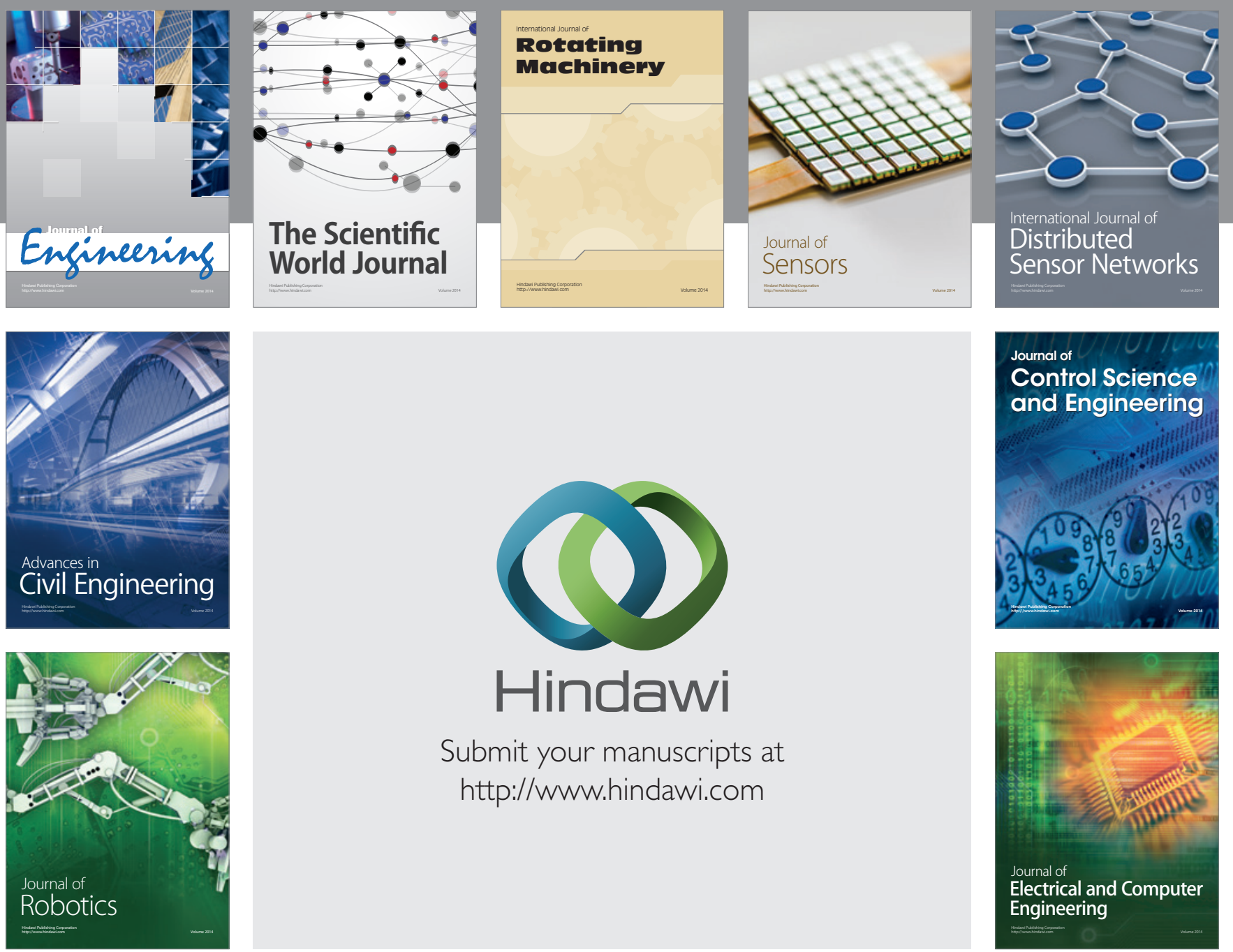

Submit your manuscripts at

http://www.hindawi.com
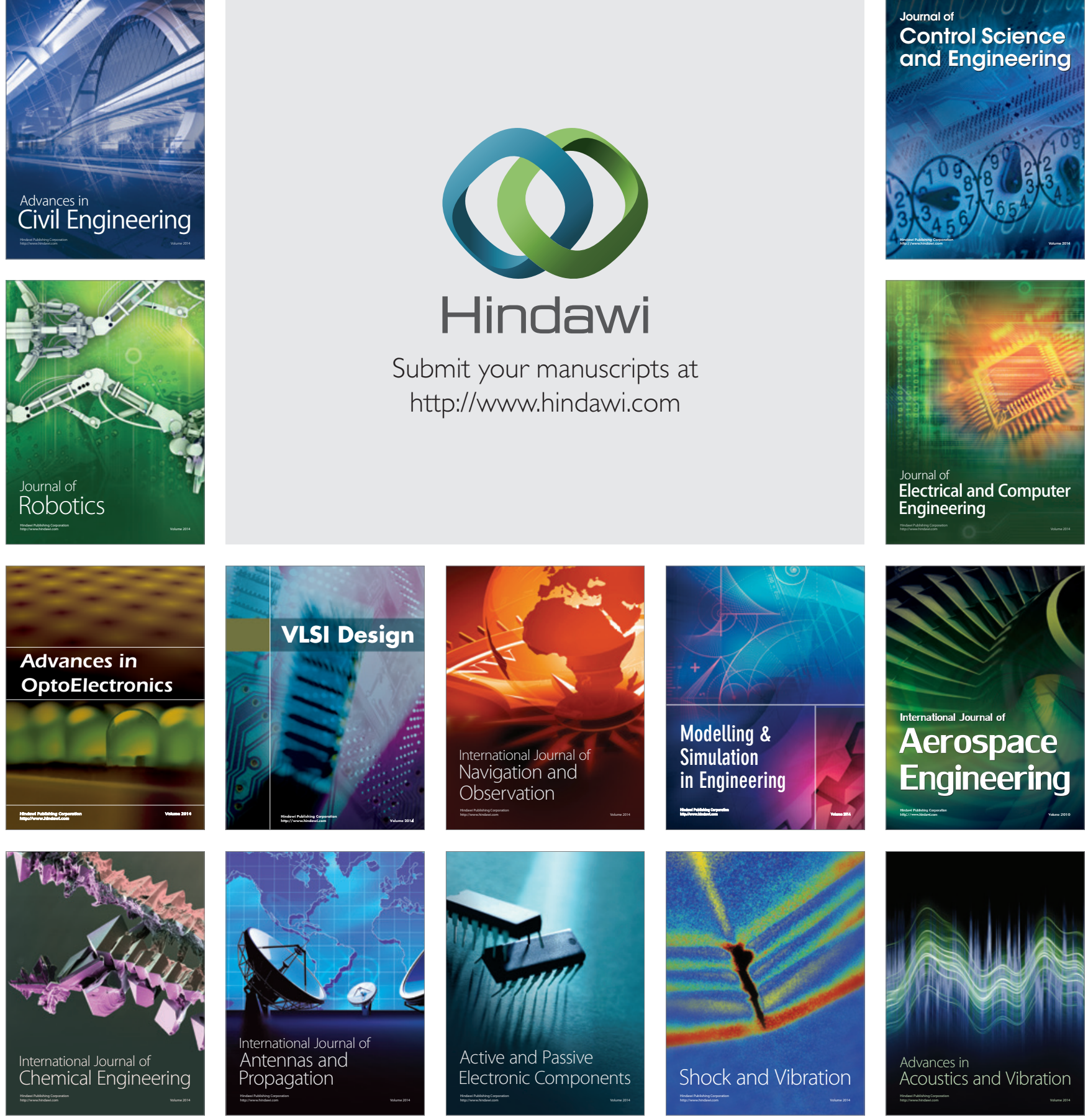